\title{
Dor crônica na velhice: manter-se ativo?
}

Dra. Fátima Ferretti (editora chefe)

Me. Márcia Regina da Silva

Dr. Clodoaldo Antônio De Sá
FisiSenectus. Unochapecó Ano 5, n. 2 - Jul/Dez. 2017 p. 1-2

Dentre as condições crônicas vivenciadas na velhice, a dor é uma das mais comuns e está associada, na maioria das vezes, a disfunções musculoesqueléticas e a lesão tecidual, interferindo negativamente na saúde do idoso ${ }^{1}$. As dores crônicas são caracterizadas como eventos persistentes com duração mínima de três meses, de natureza biopsicossocial, que se configuram como um importante problema de saúde pública, cujo enfrentamento exige uma abordagem multidisciplinar ${ }^{2}$. Em geral associada a processos patológicos crônicos que se prolongam por meses ou anos, as dores crônicas têm se tornado a principal queixa e causa de limitações funcionais nos idosos ${ }^{3}$, afetando de maneira importante a sua independência na realização das tarefas do cotidiano.

Pesquisa realizada com 451 idosos no estado do Paraná, encontrou prevalência da dor em $51,4 \%$, sendo que $38,43 \%$ referiram intensidade moderada ${ }^{1}$ e, estudo de Landmark et al ${ }^{3}$ na Noruega com 10249 idosos, identificou que 35,13\% relatavam dor crônica de intensidade moderada. Observa-se nesses estudos que a dor crônica afetou mais de $50 \%$ da população. Ainda identificou que o aumento da freqüência, duração e intensidade do exercício recreativo foi associado com menor dor crônica. Idosos que se exercitam pelo menos duas a três vezes por semana tem prevalência $27 \%$ menor de dor crônica comparados com os que não praticam exercícios físicos, sendo que as associações foram mais fortes entre as mulheres do que nos homens. 0 fato dos idosos conviverem com dor, pode provocar sofrimento e diferentes intercorrências na saúde e qualidade de vida dessa população, no entanto, mesmo com dor, o exercício físico é eficaz, se planejado de acordo com as especificidades de cada quadro clínico.

Se por um lado o sedentarismo tem sido associado com o aumento de doenças crônicas e quadros de dor, a prática de atividades físicas leve, moderada ou intensa têm sido associada positivamente com a percepção positiva de saúde de pessoas idosas ${ }^{4}$. De modo geral, a população idosa brasileira tem se preocupado em manter uma vida mais saudável, ativa e independente. O incentivo a prática de atividades e/ou exercícios físicos tem sido elencado como objetivo de diferentes políticas públicas e programas na área da saúde ${ }^{5}$, com potencial para promover uma vida saudável e com qualidade, principalmente se elas forem realizadas de maneira sistemática ${ }^{6}$. Há que se potencializar diferentes mecanismos para conscientizar e ampliar a participação dos idosos em ações, programas ou atividades que favoreçam o envelhecimento ativo.

\section{Fisiß̌enectus}




\section{Referências}

$\infty<\infty<\infty<\infty<\infty<\infty<\infty<\infty<\infty<\infty<\infty<\infty<\infty<\infty<\infty<\infty<$

1. Dellaroza MSG, Pimenta CAM. Impacto da dor crônica nas atividades de vida diária de idosos da comunidade. Cienc Cuid Saude. 2012;11 Suppl:235-242.

2. Santos FAA; Souza JB, Antes DL, OrsiI E. Prevalência de dor crônica e sua associação com a situação sociodemográfica e atividade física no lazer em idosos de Florianópolis, Santa Catarina: estudo de base populacional. Rev Bras Epidemiol. 2015;18(1):234-47.

3. Landmark T, Romundstad P, Borchgrevink PC, Kaasa S, Dale O. Associations between recreational exercise and chronic pain in the general population: evidence from the HUNT 3 study. PAIN ${ }^{\circledR}$. 2012;152(10): 2241-7.
4. LEE, I-Min. et al. Effect of physical inactivity on major non-communicable diseases worldwide: an analysis of burden of disease and life expectancy. The Lancet. EUA. Julho, 2012.

5. Lopes MA, Krug RR, Bonetti A, Mazo GZ. Barreiras que influenciaram a não adoção de atividade física por longevas. Rev Bras Ciênc Esporte. 2016;38(1):76-83.

6. Binotto MA, Tassa K. Atividade física em idosos: uma revisão sistemática baseada no International Physical Activity Questionnaire (IPAQ). Estud interdiscipl. envelhec. 2014;19(1):249-264. 